\title{
O culto a São Tiago e a legitimaÇão dA RECONQUISTA ESPANHOLA
}

Adailson José Rui

aj.rui@terra.com.br

Resumo: Ao longo da Idade Média os castelhanos desenvolveram e vivenciaram a crença no auxílio e proteção do apóstolo São Tiago contra os muçulmanos. De evangelizador o apóstolo foi transformado em guerreiro, em matamoros conforme ficou registrado em documentos e obras elaboradas na Península Ibérica ou fora dela, principalmente entre os séculos IX e XIII. Dentre essas fontes estudamos a História Compostelana, a Primera Crónica General de España e o Liber Sancti Iacobi, cuja analise nos possibilitou acompanhar tanto a forma como o culto a São Tiago foi desenvolvido, como as transformações pelas quais ele passou ao longo do tempo, vindo a servir aos propósitos da monarquia castelhana que tinha a Reconquista como uma missão régia e São Tiago como o patrono e o protetor dos cristãos no combate aos infiéis.

Palavras-Chave: Castela, Reconquista, São Tiago.

INTRODUÇÃO

Dios, ayuda, et Sanct Yague! Essa exclamação não foi uma manifestação calma e suave proferida por um fiel, mas sim um grito de guerra, expresso por um guerreiro cristão e repetido pelos seus comandados nos combates contra os muçulmanos. Esse grito de guerra demonstrava o apego e a confiança que os guerreiros cristãos tinham na proteção divina manifestada mediante as intervenções de São Tiago nos combates. Extraímos a exclamação citada da Primera Crónica General de España (p.360) elaborada sob a orientação de Alfonso X, o Sábio, rei de Leão e Castela de 1252 a 1284. O processo de elaboração da obra referida foi um marco para a historiografia ibérica. ${ }^{1}$ Rompeu com o modelo providencialista criado por Santo Agostinho e Paulo Orósio

* Doutor em História pela Universidade Estadual Paulista- UNESP-Assis.

Professor adjunto da Universidade Federal de Alfenas UNIFAL-MG.

Coordenador do Grupo de Pesquisa: Península Ibérica: da Antiguidade Tardia a Reconquista - CNPq 
seguidos pelos historiadores peninsulares, entre estes: Lucas de Tuy (? - 1249) autor do Chronicon Mundi, e o arcebispo de Toledo, Rodrigo Ximenez de Rada (1170-1247), autor de De rebus Hispaniae ou Historia gótica, obras utilizadas como fonte por Alfonso X. ${ }^{2}$

Ao elaborar a Primera Crónica General de España Alfonso X, o Sábio inovou, ao escrever em língua vulgar, a história de uma coletividade, constituída por cristãos, judeus e muçulmanos, que juntos, segundo a visão do rei, eram os promotores da história peninsular. Inovou também no trabalho com as fontes. A tradicional forma até então de escrever a história, sustentada pela cópia dos registros anteriores, sendo, na sequência, acrescentadas as informações do tempo contemporâneo, deu espaço a outra forma de trabalho. ${ }^{3}$ As informações transmitidas pelas fontes passaram a ser examinadas e organizadas, de forma a garantir que aquilo que seria relatado na crônica fosse considerado como verdade, construindo desse modo, uma memória histórica que seria útil aos interesses de quem havia escrito ${ }^{4}$. Seguindo essa perspectiva de trabalho, o rei Sábio deixou registrado o passado, de maneira a sustentar a identidade castelhana: expressa na permanência em um território específico há inúmeras gerações; na vivência do cristianismo como religião oficial; no reconhecimento da monarquia como forma de governo e na recuperação do território perdido para os muçulmanos.

Por meio da propagação do cristianismo efetivada pelo vínculo entre a Igreja e a realeza, passou a existir no Ocidente um referencial comum que integrava povos diversos em torno a valores religiosos semelhantes. $\mathrm{O}$ cristianismo, além de proporcionar a existência do vínculo entre povos diferentes, englobando-os em um mesmo universo, foi um instrumento que colaborou no processo de unificação dos povos em suas respectivas regiões. Nessa direção, o desenvolvimento de cultos aos santos foi fundamental na medida em que um santo determinado era transformado no patrono e protetor de uma região específica. Entre os castelhanos isso ocorreu com o desenvolvimento do culto a São Tiago, no qual encontraram um ponto comum que os unia e os fortalecia no desenvolvimento de um projeto também comum: a Reconquista do território perdido aos muçulmanos. ${ }^{5}$

No entanto, quem é esse santo? $\mathrm{O}$ que ou quais razões fazem dele o protetor dos cristãos no combate aos muçulmanos? Como se dá tal proteção? Entre tantas outras possíveis, as questões mencionadas nos colocam diante de uma situação: o valor e o sentido da crença no poder dos santos para o homem que vivencia esse período histórico. Segundo Andre Vauchez (1989, p. 223), "um santo é acima de tudo um morto ilustre cuja história não se conhece exactamente, mas de quem se sabe que, em vida, sofreu 
perseguições e tormentos por amor a Deus”. A tradição que afirmava: a evangelização da Hispania pelo apóstolo Tiago, o Maior; o seu retorno para Jerusalém, onde sofreu o martírio e o translado do seu corpo de Jerusalém a Galiza são um exemplo de relato de vida de alguém a quem foi atribuído o grau de santidade.

Por meio de narrativas que legitimavam a evangelização da Hispania por Tiago e que também confirmavam a autenticidade da descoberta do sepulcro contendo o seu corpo, foram reforçados a crença e o culto desse santo a partir do século IX. Neste século, a maior parte do território da Península Ibérica estava sob domínio efetivo dos muçulmanos ${ }^{6}$. É nesse contexto que os cristãos, que viviam no norte Peninsular, particularmente no reino de Astúrias, passaram a vivenciar e a difundir o culto a São Tiago.

Um dos primeiros testemunhos dessa vivência encontra-se no relato da crônica de Sampiro (século X) em que é afirmado que o rei Alfonso II (791-842) construiu a primeira igreja dedicada ao apóstolo. O encontro do corpo, de acordo com o imaginário da época, fortalecia o reino de Astúrias na medida em que conferia a ele um vínculo com o sagrado manifestado na presença das preciosas relíquias do evangelizador da Península em suas terras. No século XI, a representação de São Tiago como apóstolo e evangelizador perde espaço, pois, para ele foi desenvolvida uma nova caracterização. Foi transformado em guerreiro que, ao lado dos cristãos, combatia os infiéis. Foi transformado no "matamoros", no defensor dos cristãos que combatia os inimigos de Cristo não com palavras, mas sim com armas.

Essa transformação na forma de representação e interpretação de São Tiago ocorrida no intervalo que se estende do século IX ao século XI é um exemplo de adequação e adaptação das funções atribuídas a um santo, em função do momento vivenciado pelos fiéis. ${ }^{7}$ Essa transformação na forma de se conceber a função atribuída a São Tiago permite-nos, na condição de objeto de estudo, analisá-lo como sendo um mito, de maneira específica, um mito político.

Por mito entendemos uma criação humana, própria de cada momento e de cada cultura cuja função é explicar as interrogações postas pelo homem, integrando-os em torno a um objetivo comum. Em função do imaginário que ele cria ou ajuda a criar e a sustentar, no mito também está inserido o aspecto político, tornando-o um instrumento de uso do poder. Seguindo essa perspectiva, Manuel Garcia Pelayo, em Los Mitos Politico (1981, p.25-26) afirma que "o caráter político se faz presente no mito, independente dele ser uma criação ingênua ou espontânea ou ainda consciente e racionalizada." 
O caráter político presente no mito, independente da forma como foi criado, propicia a sua utilização como instrumento de implantação de políticas pré-determinadas, tornando-o, portanto, um objeto a ser manipulado de acordo com o interesse específico de quem o controla. São Tiago foi transformado em mito e como tal foi utilizado pelos castelhanos como fortalecedor dos ânimos no processo da Reconquista.

A abrangência assumida pelo mito de São Tiago foi além do campo religioso, no qual tem suas origens, conforme pode ser constatado nas várias fontes que nos oferecem relatos referentes à difusão e à vivência do culto ao apóstolo Tiago durante a Reconquista. Entre essas fontes, podemos citar: martirológios, cartas, histórias e crônicas. Percebemos, nessas fontes, que os elementos do campo religioso foram trabalhados de forma a dar sustentação ao campo político. Por exemplo, ao apresentar o apóstolo como sendo o evangelizador e ao afirmar que o corpo dele repousava em terras da Galiza, por um lado legitimavam e justificavam a antigüidade da evangelização da "Espanha", justificando dessa maneira as origens do cristianismo na Península, fator que reforçava a oposição aos muçulmanos vistos como infiéis. Por outro, davam valor à Igreja e à monarquia do reino de Asturias que passava a contar com uma valiosa relíquia: o corpo do apóstolo Tiago, isso em uma época em que o Ocidente não conhecia, exceto em Roma, nenhuma outra localidade onde se encontravam relíquias de um dos apóstolos de Cristo. Localizamos outro indicativo do uso político do mito de São Tiago no processo de divulgação do encontro do sepulcro contendo os restos mortais do apóstolo.

Para divulgar o encontro, foi criado um sistema de propaganda que tinha como meta, além da divulgação do precioso achado, justificar o encontro e dar autenticidade à tradição seguida pelos peninsulares referente à proteção que São Tiago lhes dedicava. Um dos primeiros documentos que testemunham a existência de subsídios para a formação de tal propaganda encontra-se no martirológio de Usuardo, monge do monastério de SaintGermain-des-Prés de Paris, composto antes do ano 867. Trata-se de um testemunho tanto da devoção dos peninsulares ao apóstolo como da formação de um imaginário que tinha na presença do seu corpo na Espanha o seu ponto de partida. Nesse martirológio, no espaço reservado ao dia $25 \mathrm{de}$ julho, dia em que se comemora o martírio de São Tiago, Usuardo anota as seguintes observações: "os santos ossos de São Tiago, levados à Espanha desde Jerusalém e depositados na região extrema, de frente para o mar britânico, são objetos de uma célebre veneração por parte daquela população"(Apud LOPES ALSINA, 1991, p.178). 
A crença na presença das relíquias do apóstolo foi fortalecida na Península e na Cristandade, mediante a divulgação do encontro do sepulcro. A primeira narrativa que trata desse assunto é uma carta destinada aos reis dos principais reinos germânicos. ${ }^{8} \mathrm{Nela}$, sem fazer nenhuma menção à pregação de São Tiago na Hispania, o autor afirma que, após a morte de Jesus Cristo, o apóstolo continuou sua pregação entre os judeus, sendo preso em Jerusalém e condenado à morte por Herodes. Conforme a carta:

en el curso del undécimo año desde la misma Pasión de Cristo, en el tiempo de los azimos, el bienaventurado apostol Santiago, trás visitar las sinagogas de los judios, fué preso en Jerusalém por el pontífice Abiatar, y condenado a muerte, junto con su discípulo Josias, por orden de Herodes. (LIBER SANCTI IACOBI, p.393)

Após apresentar, de maneira rápida, as condições em que se deu o martírio, o autor descreve como ocorreu o translado do corpo de São Tiago de Jerusalém à Galíza.

Por temor a los judios fué recogido durante la noche el cuerpo del bienaventurado apóstol Santiago por sus discípulos, que, guiados por un Angel del Señor, llegaron a Jafa, junto a la orilla del mar. Y como allí dudasen a su vez acerca de lo que debían hacer, de pronto apareció, por desígnio de Dios, una nave preparada. Y con gran alegria suben a ella llevando al discípulo de nuestro Redentor, e hinchadas la velas por vientos favorables, navegando con gran tranquilidad sobre las ondas del mar, llegaron al puerto de Iria, alabando la clemência de nuestro Salvador. (LIBER SANCTI IACOBI, p.293)

No processo de transladação e naquilo que envolve o maravilhoso, torna-se evidente a intenção do autor em apresentar a supremacia da fé cristã sobre a pagã. Um exemplo disso é a descrição dos preparativos feitos pelos discípulos de São Tiago para sepultá-lo. Após terem conseguido o lugar - um templo pagão - destruíram-no por completo e, na sequência, construíram o sepulcro do apóstolo. Nas palavras do autor da carta:

Una vez desembarcados, dejaron el muy bienaventurado cuerpo que transportaban en un pequeño prédio llamado Libredón, distante ocho millas de la citada ciudad [Iria], y en donde ahora se venera. Y en este lugar encontraron un grandísimo ídolo construído por los paganos. Rebuscando por allí encontraron una cripta en la que había herramientas con las que los canteros suelen construir las casas. Asi, pues, los mismos 
discípulos, con gran alegria, derruyeron el citado ídolo y lo redujeron a menudo polvo. Después, cavando profundamente, colocaron unos cimientos firmísimos y levantaron sobre ellos una pequeña construcción abovedada, en donde construyeron un sepulcro de cantería, en el que, con artificioso ingenio, se guarda el cuerpo del Apóstol. (LIBER SANCTI IACOBI, p.293)

Tal descrição é feita de maneira a relacionar o lugar e a estrutura construída com a sua "descoberta" por volta de 810 . O caráter explicativo da narrativa pode ser notado, também, pelo fato de o autor pretender não deixar dúvida quanto à construção do sepulcro. Para tanto, indica até como encontraram os recursos materiais para a sua construção. O rigor presente na descrição funcionou como um instrumento que auxiliava na legitimação do encontro do corpo e, também, da evangelização da Península por São Tiago.

O empenho em elaborar relatos sobre a evangelização, o martírio e o translado do corpo de São Tiago de Jerusalém para terras peninsulares e referentes ao encontro do sepulcro contendo o corpo do apóstolo, tornou-se algo necessário na sustentação de uma estória que deveria ser considerada história. Essa "realidade" funcionava como um poderoso instrumento que, em uma direção, constantemente unia e fortalecia os cristãos castelhanos para o combate aos muçulmanos e, por outro, atraía peregrinos e guerreiros de outras terras que, motivados pela busca de graças, se somavam às forças locais no combate ao infiel. É também na perspectiva de dar legitimidade à relíquia que entendemos a necessidade que se teve de descrever, em 1077, a forma como foi localizado o sepulcro de São Tiago.

No ano referido foi firmado entre o bispo Diego Peláez e o abade do monastério de San Payo de Antealtares um acordo que ficou conhecido como "Concórdia de Antealtares". Por meio desse documento, foram estabelecidas as normas para ser construída a Catedral românica de Santiago. A importância da construção e a legitimidade para que ela ocorresse naquele lugar é atestada pela descrição da localização do sepulcro e de como ele foi encontrado. Conforme descrito, os anjos revelaram a um ermitão chamado Pelayo o lugar em que São Tiago estava sepultado. A revelação deu-se de forma maravilhosa: luzes sobrenaturais apareceram sobre o local onde os anjos haviam indicado que estaria o sepulcro. Diante de tais manifestações sobrenaturais, os fiéis da igreja de São Félix recorreram a Teodomiro, bispo de Iria Flávia (atual Padrón) e este, após três dias de jejum e orações, dirigiu-se, juntamente com os fiéis, ao local mencionado e encontrou o corpo do apóstolo, confirmando a revelação feita pelos anjos a Pelayo. Essa descrição 
completa uma espécie de quadro composto pela divulgação da pregação realizada por Tiago na Hispânia, pelo martírio do apóstolo e pelo encontro do seu corpo no local que ficaria conhecido como Santiago de Compostela. O empenho em elaborar os relatos referidos foi visto como algo necessário para a sustentação de uma crença que deveria ser considerada como fundamentada na realidade. Legitimava-se assim o real vínculo do apóstolo Tiago com a Hispânia e, de maneira específica, da presença do seu corpo em Compostela. Nesta direção são significativas duas elaborações realizadas no século XII: a Historia Compostelana9e o Liber Sancti Iacobi. ${ }^{10}$

A Historia Compostelana foi elaborada pelos canônicos da Igreja de Santiago de Compostela, entre 1100 e 1139, a mando do arcebispo Diego Gelmirez. Relata os feitos para engrandecer a Igreja e a Cidade de Santiago de Compostela realizados por Gelmirez, tanto como bispo como arcebispo. Por ser um registro de acontecimentos contemporâneos aos autores, a História Compostelana em si é um testemunho da importância atribuída a São Tiago no século XII, pois, o arcebispo Diego Gelmirez fundamentou todas as suas realizações tendo como sustentação o fato de presidir a Igreja de Santiago de Compostela, onde estava o corpo do apóstolo Tiago, o evangelizador da Hispania e protetor dos castelhanos no combate aos muçulmanos. Tendo como base esses pontos sustentados pela crença, ele justifica e desenvolve as ações de liderança, tanto temporal como espiritual, nos seus domínios. $\mathrm{O}$ registro, que para a época comprova esse fato encontra-se no $1^{\circ}$ e no $2^{\circ}$ capítulo da Historia Compostelana, elaborados por Munio Alfonso (1994, p. 66-67). Nos capítulos referidos foram relatados o martírio e o translado do corpo de São Tiago, de Jerusalém a Compostela, local onde foi sepultado. Como fontes, o autor seguiu relatos produzidos anteriormente, fundamentados nos escritos de São Lucas, nos Atos dos Apóstolos e na carta, referente ao translado. Mesmo não fazendo referência à evangelização da Espanha por São Tiago, essa última fonte -a carta- é utilizada por Munio Alfonso, que visando apresentar como se deu o encontro do corpo e atestar a sua veracidade, amplia as informações transmitidas por ela, reescrevendo-a de forma que os argumentos nela contidos, também explicassem os motivos pelos quais o sepulcro caiu no esquecimento dos cristãos, sendo descoberto vários séculos depois do sepultamento, em cujo local foi levantada a Igreja de Santiago de Compostela, garantindo dessa maneira o poder de quem a presidia.

Habia florecido desde antiguo la religión Cristiana en aquel lugar entre los seguidores de la Fe católica, pero al llegar el tiempo de la persecución y pisotear la soberbia tirania de los paganos la dignidad del nombre 
cristiano casi todo el culto de la religión Cristiana se habia perdido hacia ya mucho tiempo. Asi pues, en época de los sarracenos y largo tiempo después de la restauración, la venerable tumba del santo apóstol, que no era visitada por ningun Cristiano, permaneció cubierta durante muchísimo tiempo por la espesura de los arbustos y del bosque y no fue revelada o conocida por nadie hasta la época de Teodomiro, obispo de Iria.(FALQUE REY, 1994, p. 68)

Outra obra que atesta a vivência e a utilização do mito de São Tiago é o Liber Sancti Iacobi, cuja finalidade é exaltar o poder e os feitos do apóstolo. Realizações que serviam como meio de atração de peregrinos tanto peninsulares como, principalmente, do além Pirineus. Seguindo o propósito de divulgar a presença em Compostela das relíquias do apóstolo e também de divulgar os milagres realizados pelo santo, a obra foi amplamente divulgada nas rotas de peregrinação.

Integra o conteúdo do Liber Sancti Iacobi relatos referentes ao martírio, ao translado do corpo do apóstolo e ao seu sepultamento. Trata-se de uma narrativa divergente da apresentada na Historia Compostelana; ao contrário desta, é repleta de detalhes. Isso pode ser explicado pelo seguinte fator: a Historia Compostelana é uma obra oficial, na qual o caráter propagandista também se faz presente, no entanto, esse caráter está centralizado nos feitos de Diego Gemirez, e não naquilo que envolve "a descoberta" do corpo. ${ }^{11}$ Visase destacar as realizações do arcebispo de Compostela, e não as realizações do santo. Já o Liber Sancti Iacobi, como fora mencionado, caracteriza-se por ser uma obra de divulgação do culto a São Tiago e das peregrinações até o seu sepulcro. Esse objetivo fez com que os seus autores apresentassem, na narrativa do translado, situações que propiciavam a exaltação da fé e da conduta cristã da época, fatores que favoreceram o enriquecimento da narrativa e que permitem com que nós venhamos a conhecer mais sobre o imaginário daquele período.

Em síntese, é relatado no Liber Sancti Iacobi que, após a ressurreição de Jesus Cristo, os apóstolos se dividiram e saíram com a missão de evangelizar o mundo. Tiago foi para a Espanha, onde, com muitas dificuldades, fez nove discípulos, voltando depois a Jerusalém com sete deles. Nessa cidade, foi condenado por Herodes Agripa e, como consequência, foi degolado.

À noite, após o martírio do apóstolo, os discípulos dele, que também estavam em Jerusalém, colocaram-no em um barco que milagrosamente navegou durante seis dias até chegar ao noroeste da Península Ibérica. No porto, o corpo se elevou cercado de luzes e se dirigiu para o lugar onde seria sepultado. Conduzidos por um anjo, os discípulos o encontraram nos 
domínios de Luparia, uma senhora pagã. Essa senhora, antes de admitir que o sepultassem em suas terras, mandou que os discípulos pedissem autorização ao rei. Ele, por sua vez, sabendo que se tratava de cristãos, perseguiu-os até uma ponte que, sem ter causas específicas, caiu justamente no momento em que os soldados perseguidores a atravessavam. $\mathrm{O}$ rei interpretou esse fato como uma manifestação divina, mediante a qual, juntamente com o seu reino, converteu-se ao cristianismo. Após esse episódio, os discípulos voltaram a Lupária e ela os mandou buscar alguns touros para ajudá-los na construção da sepultura. No caminho até o local onde estavam os touros, os discípulos encontraram um dragão. Por meio do sinal da cruz o venceram e, com o mesmo sinal, amansaram os touros e voltaram com eles para construir o sepulcro do apóstolo. Quando Lupária tomou conhecimento dos prodígios acontecidos - vitória sobre o dragão e a domesticação dos touros-, converteu-se ao cristianismo e permitiu que o sepultamento acontecesse. (LIBER SANCTI IACOBI, 1992, p. 386-392)

A narrativa sintetizada aqui é caracterizada pela presença do maravilhoso, manifestado em sinais e símbolos que fazem parte da mentalidade medieval. ${ }^{12}$ Como exemplo dos perigos que faziam parte desse imaginário, os autores apresentam: a força da natureza, as ondas, as rochas que dificultavam e ameaçavam a navegação; os animais (os touros); os não fiéis a Cristo, representados na narrativa, pelo rei Dugio e seus soldados e por Lupária e, ainda, pelo monstruoso, o dragão, uma das representações do demônio no imaginário medieval. Em contrapartida aos perigos, apresentam a força de Deus manifestada na presença do corpo de São Tiago, que transmite segurança expressa na proteção aos discípulos do apóstolo contra os perigos oferecidos pelo mar durante o seu translado; na queda da ponte, ao serem os discípulos perseguidos tanto pelo rei como pelos seus guerreiros, sendo esse prodígio equiparado ao acontecido com o exército do faraó ao perseguir Moisés e os hebreus que saíam do Egito; na cruz e no seu efeito como sinal, que amansa os touros e afugenta o dragão.

Perspectiva diferente quanto à forma de apresentar São Tiago e aquilo que com ele está relacionado, encontramos nas crônicas nas quais esta registrada a história peninsular. Por serem obras que visam registrar a história do reino, ou até mesmo da Península como um todo, a temática São Tiago nelas aparece como um elemento importante, porém, não único. Na Crônica de Sampiro, elaborada no século X, encontra-se a primeira referência direta sobre o descobrimento do sepulcro de São Tiago. Segundo Luis Vazquez de Parga, na Crônica referida, é relatado que "no ano de 872, Alfonso III havia derrubado a pequena igreja [de São Tiago] levantada ali por 
Alfonso II, o Casto, de pedra e barro, para construir outra de pedra lavrada e cimento com colunas e bases de mármore". (VAZQUEZ DE PARG; URIA RIU, 1948, p. 28-29). Já a Crônica Silense, elaborada no século XII, além de manter indiretamente a afirmação do encontro do sepulcro de São Tiago traz a primeira descrição de uma aparição do apóstolo. Segundo essa obra, São Tiago aparece sob a forma de guerreiro, cavalgando sobre um cavalo branco e espada reluzente na mão. Será essa a imagem iconográfica predominante de São Tiago na Península Ibérica.

No século XIII, referências a São Tiago serão apresentadas no Chronicon Mundi de Lucas de Tuy e na História Gótica de Rodrigo Ximenes de Rada. Ambas, juntamente com outras fontes, foram utilizadas por Alfonso $\mathrm{X}$, o sábio na elaboração da Primeira Crônica General de España. Essa última obra contém vários relatos referentes à presença de São Tiago em batalhas da Reconquista. Nesses relatos, mantém-se a caracterização apresentada na Crônica Silense. O santo é apresentado como o guerreiro enviado por Jesus Cristo para proteger os cristãos dos inimigos da fé. Para fortalecer essa definição, é apresentado um relato no qual um bispo, proveniente da Grécia e peregrino em Santiago de Compostela, denominado Estiano, discute com os demais peregrinos a caracterização do santo. Para ele a representação do apóstolo não é a de guerreiro, mas sim a de pescador, conforme narrado nos evangelhos. Para solucionar a discussão, quando o bispo dormia, São Tiago aparece em sonho e afirma:

Estiano, tu tienes por escárnio porque los romeros me llamam cauallero, et dize que lo non so, et por Esso uin agora a ti a mostrarteme por que nunqua iamas dubdes que yo non so cauallero de Cristo et ayudador de los cristianos contra los moros". (PRIMERA CRÓNICA, 1995, p. 487)

A crônica elaborada sob a orientação de Alfonso X já tem definida e concretizada a caracterização de São Tiago como guerreiro. Nela não se faz referência a São Tiago como peregrino, conforme descrito no Liber Sancti Iacobi.

Enfatizando a presença de São Tiago em batalhas da Reconquista e registrando por meio da historiografia essa presença, a monarquia castelhana tem o herói de que precisa, isto é, tem um elemento concreto que atesta e legitima as ações deles contra os muçulmanos e que também promove a união entre os cristãos comandados pelo monarca em torno de um mesmo objetivo. Em virtude do momento em que viviam, os castelhanos precisavam de um guerreiro e não de um pescador, evangelizador ou mesmo de um peregrino. 
Essa forma de pensar o uso do santo faz parte de uma ideologia que tinha por objetivo apresentar e justificar a importância dos momentos em que o apóstolo São Tiago aparece. São cinco os relatos referentes a aparições do santo como ente celeste que atuou a favor dos castelhanos na luta contra os muçulmanos. ${ }^{13}$ Os momentos em que, segundo os relatos, ocorreram as aparições são decisivos tanto na questão em si, vencer os muçulmanos, quanto na perspectiva de exaltação das forças castelhanas no sentido de deixar marcados na memória determinados acontecimentos que testemunham o empenho e a dedicação e até mesmo a sacralização da missão de reconquistar o território perdido dos infiéis. Como exemplo apresentamos o relato sobre a batalha de Clavijo, ocorrida durante o reinado de Ramiro I (842-850). Conforme a Crônica (1995, p. 360):

Et ellos faziendo sus orationes adurmiose el rey Don Ramiro, et appareciol estonces en suennos ell apostol Sant Yague et dixol: 'sepas que Nuestro Sennor Jhesu Cristo partio a todos los otros apostoles mios hermanos et a mi todas las otras províncias de la tierra, et a mi solo dio a Espanna que la guardasse et la amparasse de manos de los enemigos de la fe'. Pues que el apostol ouo dicho al Rey Don Ramiro estas palavras, allegose mas a ell, et tomol a la mano et apretogela ya quando et dixol de cabo: 'rey Ramiro esfuerça en tu coraçon et sey bien firme et fuerte en tus fechos ca yo so Yague ell apostol de Jhesu Cristo et uengo a ti por ayudarte contra estos tus enemigos. Et sepas por verdad que tu uencras en la mannana con la ayuda de Dios a todos estos moros que te agora tienen cercado. Et digote que tomaran y muerte muchos de los tuyos, a los que esta apareiada la gloria de Dios et la su folgança que siempre durara. Et porque non dubdes nada en esto que te yo digo ueer medes cras andar y en la lid en un cauallo Blanco con uma Senna blanca, et grand espada reluziente en la mano. Et uos luego por la grand mannana confessaruos edes de todos uestros peccados muy bien, et recibredes el cuerpo et la sangre de Nuestro Sennor Dios et nuestro Saluador; et pues que esto ouieredes fecho, non dubdes nada de ferir en la hueste de los bárbaros, llamando Dios, ayuda, et Sant Yague! Ca ciertamentre sepas que todos los metredes a espada et los mataredes. Pues que lesto ouo dicho, ell apostol se tiro delante, et fizo luego llamar los obispos et los abades et todos los altos omnes de su hueste, et dixoles aquella vision que viera.

Esse relato nos oferece não só a idéia da presença de São Tiago aos cristãos, como também todas as implicações de uma mentalidade que busca a mediação do sagrado. Põe de manifesto uma religiosidade que relaciona os homens com Deus por meio da vassalagem. Os guerreiros devem cumprir 
certos ofícios religiosos como rezar, confessar e comungar, para fazer com que o santo intervenha junto a Deus para conseguir a vitória e o paraíso para aqueles que viessem a morrer no combate. Isso demonstra-nos uma relação de pacto, de troca e até de barganha. A mentalidade clerical, o domínio do clero e dos monges como meios de impor a mediação também se faz presente. Podemos ainda destacar a importância desse relato porque ele reafirma as formas iconográficas que representavam São Tiago como guerreiro montando um cavalo branco, portando uma espada e um estandarte branco.

No entanto, o relato referido não foi elaborado logo após a batalha de Clavijo, mas sim cerca de três séculos depois. Segundo Claudio Sanchez Albornoz, a aparição de São Tiago em Clavijo é um relato produzido no século XII com o objetivo de satisfazer necessidades impostas por este século. ${ }^{14}$ Nessa perspectiva, em uma direção o relato vai ao encontro da satisfação de uma necessidade desenvolvida a partir do século XI que consistia em vincular e difundir cada vez mais o vínculo entre São Tiago e a Península, fator que acentuava o caráter sagrado atribuído à Reconquista. Em outra, fortalecia a monarquia que era apresentada e legitimada como a condutora do processo da Reconquista. É ao rei que São Tiago aparece, é a ele que faz as recomendações. Se pensarmos em uma estrutura de forma hierárquica, teremos, em primeiro lugar, São Tiago como o enviado de Deus que comunica ao rei as condições a serem observadas para a obtenção da vitória. Em segundo lugar, está o rei que ouve as recomendações feitas pelo santo. Em terceiro, encontram-se os integrantes da Igreja que aparecem como os intermediários entre o rei e os guerreiros. Dessa maneira, os integrantes da Igreja ficavam abaixo do rei, embora a monarquia buscasse apoio no campo religioso. Ao rei ficava garantido o topo da hierarquia social colocando os clérigos ao serviço dele.

Entre os castelhanos, os relatos referentes a aparições de São Tiago serviram como forma de exaltar os ânimos direcionando-os para a vitória e também como um instrumento que auxiliava na divulgação da presença das relíquias do santo em Compostela, fator que contribuía para a atração de peregrinos, povoadores, comerciantes e, de guerreiros provenientes do além Pirineus que almejavam se juntar às forças castelhanas para com elas lutarem contra os infiéis. ${ }^{15}$

A monarquia castelhana encontrou no mito de São Tiago a sustentação para integrar e mobilizar os castelhanos e outros cristãos, peninsulares ou não, em prol da Reconquista e, ainda, para explicar sua permanência e sua missão de reconquistar os territórios anteriormente perdidos aos muçulmanos. 
The cult of St. James and the Legitimization of Spanish Reconquest

Aвstract: Throughout the Middle Ages and experienced the Spaniards developed a belief in the aid and protection of the apostle St. James against Muslims. Evangelist of the apostle was transformed into a warrior in "matamoros" as it is recorded in documents and works produced in the Iberian Peninsula or outside, especially between the ninth and thirteenth century. Among these sources we have studied the Historia Compostelana, Primera Crónica General de España and the Liber Sancti Iacobi, whose analysis allowed us to monitor how much the cult of St. James was developed as the transformations through which he passed over time, been serve the purposes of the Castilian monarchy that had the Reconquest as a royal mission and St. James as a patron and protector of christians in the fight against infidels.

KeY wORDs: Castile, Spanish Reconquest, Saint James.

\section{NotAs}

1 Para a compreensão da forma como a história era escrita na Idade Média é significativo a obra: MITRE FERNANDEZ, 1982. Já, entre os estudos recentes sobre a forma de escrever a história adotada por Alfonso X, o Sábio é relevante o artigo: FERNANDEZ-ORDÓÑEZ, 2009.

2 Entre as fontes utilizadas por Alfonso X para a elaboração da Primera Crónica General de España, encontram-se Cantares de Gesta, Histórias, Lendas, Poemas, narrativas muçulmanas, relatos conservados pela tradição oral, Cartulários, Crônicas. Sobre o processo de elaboração da Primera Crónica General de España veja: RUI, 2000, p. 211-217.

3 Sobre a forma com a história era escrita na Idade Média veja, POMIAM, 1975 n, 5 p. 935-952; ORCASTEGUI, SARASA, 1991. A perspectiva apresentada por Pomiam é apresentada também por Enrique Jerez Cabrero ao estudar o Chronicon Mundi de Lucas de Tuy. Sobre esse tema, veja: JEREZ CABRERO, 2006.

4 Sobre a criação da memória histórica, veja: SESMA MUÑOZ, 2003, p. 13-32.

5 Sobre a temática Reconquista, veja: GONZÁLEZ JIMÉNEZ, 2003, p. 151- 170; VALDEÓN BARUQUE, 2006; NOGUEIRA, 2001, p. 277-295.

6 Sobre a presença dos muçulmanos em território ibérico, veja: CARRASCO MANCHADO, 2009.

7 Tendo como contexto a Península Ibérica e o intervalo mencionado - séc. IX ao séc. XI - temos que considerar duas realidades: a cristã e a islâmica. No intervalo referido o mundo islâmico Ibérico passa de momentos de crise à desagregação total, culminando com o fim do califado de Cordoba em 1031. 
Movimento contrário foi desenvolvido no mesmo intervalo de tempo nos reinos cristãos do norte peninsular. Da resistência aos muçulmanos passaram ao ataque, fundamentando e legitimando a Reconquista. É nesse contexto que a representação e a função atribuídas a São Tiago foram alteradas: de evangelizador e peregrino foi transformado em guerreiro e "matamoros".

8 Não se sabe ao certo quem foi o autor desta carta. Conforme nota da edição de 1992 do Liber Sancti Iacobi, para López Ferreiro, poderia ter sido o Papa Leão III (795-816). P. Fita e Fernandez Guerra tendem a aceitar Leão IX (1049-1054 ) ou Leão VIII (963-65) como prováveis autores (LIBER Sancti Iacobi 'Codex Calixtinus'- MORALEJO et. Al. (org.) Reedição X. Carro Otero. Pontevedra: Xunta de Galicia, 1992, p. 383). A esse mesmo respeito, Emma Falque Rey, em notas à Historia Compostelana, indica a obra de Fernando Lópes Alsina, La Ciudad de Santiago, na qual ( páginas 121 a 126 e 187 a 189) o autor atribui a essa carta a categoria de "Pseudo epistola" elaborada por Leão, Patriarca de Jerusalém (FALQUE REY, E. (ed.) Historia Compostelana. Madrid: Akal, 1994, p. 67).

9 (FALQUE REY, E. (ed.) Historia Compostelana. Madrid: Akal, 1994, p. 7.

10 O Liber Sancti Iacobi foi elaborado por volta de 1160 em Cluny ou em uma abadia a ela vinculada. Seu provável autor foi Aimerico Picaud, no entanto, a autoria oficial foi atribuída ao Papa Calixto II (1119-1124). Sobre essa obra, veja: DIAZ Y DIAZ, M.C. El Codice Calixtino de la Catedral de Santiago. Estudio Codicologico $y$ de contenido. Santiago de Compostela: Centro de Estudios Jacobeos, 1988. I HERBERS, K. Der Jakobuskult dês 12 Jahrhunderst und der "Liber Sancti Iacobi". Studien über das verhältnis zwichen Religion und Gesellshaft im Hohen Mittelalter. Wiesbaden: Steiner, 1984.

11 A Historia Compostelana é uma combinação de gesta e registrum, pois é constituída pelos documentos que entraram na Igreja de Santiago e por comentários de acontecimentos contemporâneos, que, de alguma forma, estavam relacionados a ela. In: FALQUE REY, E. (ed.) Historia Compostelana. Madrid: Akal, 1994, p. 23.

12 Entendemos como maravilhoso a crença do homem medieval em forças sobrenaturais, sejam elas maléficas ou benéficas. Cf. LE GOFF, J. O maravilhoso e o cotidiano no Ocidente Medieval. Lisboa: Edições 70, 1985.

13 Conforme narrado na Primera Crónica General de España, as aparições de São Tiago aconteceram nos segintes momentos: Batalha de Clavijo, relatada nas páginas 359-361; confronto entre Fernan Gonçales e Almançor relatado nas páginas: 403-6; Reconquista de Coimbra, relato presente nas páginas: 486-8; Morte de El Cid e o cerco de Valência relato nas páginas: 636-8 e no confronto entre o infante Alfonso, futuro Alfonso X e Abenhut, líder dos muçulmanos. Relato presente nas páginas: 726-9

14 SANCHEZ ALBORNOZ, C. Santiago Hechura de España. Salamanca: Fundación Sanchez Albornoz, 1993. 
15 Com referência ao olhar do além Pirineus sobre o culto a São Tiago, tornase significativo destacarmos que entre esses a crença está relacionada com o apóstolo, isso é, a imagem que se tem de São Tiago é a do peregrino e evangelizador e não a de guerreiro. Testemunha dessa maneira de conceber o santo, a encontramos, na Legenda Aurea, a hagiografia elaborada na segunda metade do século XIII por Jacopo de Varazze. Nessa obra, relativo a São Tiago é relatada a sua ida à Espanha para evangelizá-la; o retorno para Jerusalém e os enfrentamentos que teve com o mago Hermógenes; o martírio e o translado do corpo do apóstolo para a Galiza. O relato referido encontra-se em VARAZZE, Jacopo. Legenda Aurea. Vidas de Santos. Tradução do latim, apresentação, notas e seleção iconográfica de Hilário Franco Júnior- São Paulo: Companhia das Letras, 2003, p. 561-570.

\section{REFERÊNCIAS}

Diaz Y Diaz, M. C. El Codice Calixtino de la Catedral de Santiago. Estudio Codicologico y de contenido. Santiago de Compostela: Centro de Estudios Jacobeos, 1988.

Falque Rey, E. (ed.) Historia Compostelana. Madrid: Akal, 1994.

Fernandez-Ordóñez, Inés. De la historiografia fernandina a la alfonsí. Edición digital. Alicante: Biblioteca Virtual Miguel de Cervantes, 2009.

Garcia-Pelayo, M. Los Mitos Politicos. Madrid: Alianza Editorial, 1981.

González JimÉnez, Manuel. Sobre la Ideologia de la Reconquista: Realidades Y Tópicos. In: Iglesia Duarte, José Ignacio de la (coord.) Memoria, Mito Y Realidad en la Historia Medieval. XIII Semana de Estudios Medievales Nájera 2002. Logroño: IER, 2003, p. 151- 170.

Herbers, K. Der Jakobuskult dês 12 Jahrhunderst und der "Liber Sancti Iacobi". Studien über das verhältnis zwichen Religion und Gesellshaft im Hohen Mittelalter. Wiesbaden: Steiner, 1984.

Jerez Cabrero, Enrique. El Chronicon Mundi de Lucas de Tuy (c.1238): Tecnicas compositivas y motivaciones Ideológicas. Dpto. Filologia Española (Fac. Filosofia y Letras) Universidad Autónoma de Madrid. Julio 2006 (Tese de Doutorado).

LE GoFf, Jacques. O maravilhoso e o cotidiano no Ocidente Medieval. Lisboa: Edições 70, 1985.

Liber Sancti Iacobi 'Codex Calixtinus'. Moralejo et, Al. (org.) Reedição X. Carro Otero. Pontevedra: Xunta de Galicia, 1992

Lopes Alsina, F. Los espacios de la devoción, peregrinos y romeros en el antiguo reino de Galizia. In: Viajeros, Peregrinos, Mercaderes en el Ocidente Medieval. XIII 
Semana de Estúdios Medievales- Estella 91. Pamplona, gobierno de Navarra, 1991, p.178.

Mitre Fernandez, Emílio. Historiografia y mentalidades históricas em la Europa Medieval. Madrid: Universidad Complutense, 1982.

NogueIra, Carlos Roberto F. A Reconquista Ibérica: a construção de uma ideologia. Historia, instituciones, documentos. n. 28, 2001, p. 277-295.

Orcastegui, Carmen \& Sarasa, Esterban. La historia en la Edad Media. Historiografia e hiostoriadores en Europa Occidental: siglos V-XIII. Madrid: Catedra, 1991

Pomiam, K. L'Histoire de La Science et l'Histoire de La Histoire. Annales E.S.C. Paris: Armand Colin, 1075 n5 p. 935-952.

Primera Crónica General de España. Que mando componer Alfonso X, el Sabio y que se continuaba bajo Sancho IV en 1289. Menendez Pidal, Ramón (publ.) Madrid: Gredos, 1955, p.360.

RuI, Adailson. José. A elaboração da História na Idade Média: o exemplo de Alfonso X, o Sábio. In: De Boni, Luiz Alberto (org.). A Ciência e a organização dos Saberes na Idade Média. Porto Alegre: Edipucrs. 2000, p. 211-217.

Sanchez Albornoz, Claudio. Santiago Hechura de España. Salamanca: Fundación Sanchez Albornoz, 1993.

Sesma MuÑoz, Ángel. La creación de la memória historica, uma selección interesada del pasado. In: IgLesia DuARTE, José Ignacio de la - Memoria, mito y realidad em la historia medieval. XIII Semana de Estudios Medievales- Najera, 2002. Logroño: IER, 2003, p. 13-32.

VAldeón BARUQue, Julio. La Reconquista el concepto de España: unidad y diversidad. Madrid: Espasa-Calpe, 2006.

Varazze, Jacopo. Legenda Aurea. Vidas de Santos. São Paulo: Companhia das Letras, 2003.

VAucheZ, Andre. O Santo. In: LE GOFF, Jacques (org.) O Homem Medieval. Lisboa: Presença, 1989.

Vazquez De Parga, L.; Lacarra, J. M.; Uria Riu, J. Las Peregrinaciones a Santiago de Compostela. Madrid: C.S.I.C. 1948. 